\title{
Online medical blogging: don't do it!
}

$\mathrm{M}$

ark, a resident in emergency medicine, had a rough day at work. One of his patients was very dissatisfied with his care, in part because of the long wait before he was seen, emergency department staff gave him a hard time for not putting away his charts, referring services felt some of his referrals were inappropriate and his staff mentioned that he had to pick up his pace. When he got home, he went onto a popular online social networking website, and updated his electronic profile. Without mentioning anyone by name, he complained about his department, the hospital, the university and the emergency department patients.

His online blog was seen by a recent patient of the hospital, who became quite insulted and subsequently irate. The patient mailed complaint letters to the emergency department, hospital, university and Royal College of Physicians and Surgeons. For Mark, the resident, a difficult time was about to begin.

Though a fictitious scenario, this could certainly occur. It is quite clear that physicians and medical trainees may not use information that could identify a patient in such a setting without the patient's permission. However, where is the line drawn when it comes to posting a commentary online related to the practice of medicine?

There are 3 aspects to this issue. The first concerns professionalism. Many would argue that physicians have both a powerful position and leadership role to fill in society, and must work that much more diligently and nimbly to acquire and maintain the trust of the public, including acting in a professional manner. Telling personal stories about individual patients poses the risk of eroding the public's trust in the particular physician

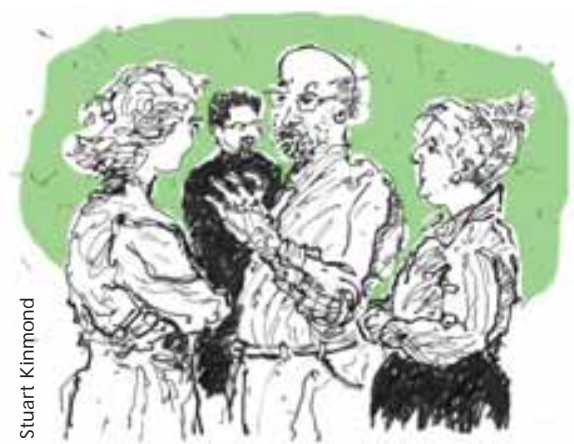

involved, as well as in the relevant department, hospital and university, and in physicians in general.

The second concerns freedom of speech. There are clear rules about posting or using patients' identifying information. However, limiting what physicians write about in terms of their experiences either in practice or in training, becomes at some point censorship. There is no law that requires one to enjoy one's profession and there is a law that is meant to protect freedom of speech. If patients have a problem with a physician complaining, some may argue that they could find another physician.

Regulatory and policy-setting bodies are debating these first 2 components. However, there is a third component self-protectionism - where we wish to make our point.

Why would you, as a physician, put yourself in a precarious position by posting personal feelings, opinions, and attitudes on a public website? Material that may seem innocent enough at the time of posting may come back to haunt you at any point in your career, by any person you have or have not yet met weeks, months, years or even decades down the road. And, you cannot know who may have - or develop - a grudge against you. The people you may be writing about are patients with illness. They may be emotionally vulnerable or even unstable. As such they may seek to contact or confront you outside the work place. Giving those people a permanent electronic record about yourself may allow them to pursue you in ways you will not like. Many online posters may consider Internet media as temporary; however, Internet content is still published, and should be considered permanent.

We would draw an analogy to email. It is generally a smart idea to avoid including sensitive information or angry comments in email communications because a single (unintentional or intentional) click of the mouse by the receiver can disseminate the comments to anyone in the world.

Soon, we will surely have a clear directive from the relevant medical bodies on this issue. In the meantime, our advice would be to play it safe - do not post such information online for all to see. Keep your stories, complaints, medically related commentary and your tongue-in-cheek dialogue for your personal friends.

\section{Mark Otto Baerlocher MD \\ Radiology Residency Training \\ Program \\ University of Toronto \\ Toronto, Ont. \\ Allan S. Detsky MD \\ Department of Health Policy \\ Management and Evaluation \\ University of Toronto \\ Toronto, Ont.}

Have you got an opinion about this article? Post your views at www.cmaj.ca. Potential Salon contributors are welcome to send a query to salon@cma.ca. 